\title{
Acidentes em rodovias tradicionais e estradas parques
}

Accidents on traditional highways and park roads

Accidentes en carreteras tradicionales y carreteras parques

Matheus Soares Keller Graduando, UNESP Ilha Solteira, Brasil matheusskeller@gmail.com

Jairo Lima Professor Assistente Doutor, UNESP Ilha Solteira, Brasil jairo@dec.feis.unesp.br 


\section{RESUMO}

A análise dos acidentes pode fornecer informações fundamentais capazes de promover o planejamento e a construção de instalações e equipamentos, as operações viárias, e as ações para aumentar a segurança nas estradas, sobretudo nos trechos localizados no interior de unidades de conservação. Neste trabalho estudam-se acidentes rodoviários na Rodovia Estadual SP 613, com ênfase nos trechos próximos e no interior do Parque Estadual Morro do Diabo (Teodoro Sampaio, SP). Os dados obtidos revelam que no período de 2012 a 2016,16\% dos acidentes com animais na SP 613 ocorreram no trecho da Estrada Parque Morro do Diabo. Observou-se uma redução dos acidentes a partir de 2015 que pode estar relacionada à instalação de dispositivos de controle de velocidade (lombada eletrônica) no trecho da Estrada Parque. Os resultados reforçam a importância da implantação de medidas para a proteção a fauna silvestre nas estradas, especialmente em áreas naturais ricas em biodiversidade como as unidades de conservação. Contudo, ressalta-se a necessidade de que o monitoramento sistemático dos acidentes em geral seja continuamente efetuado, de modo a permitir melhor avaliar a eficácia das medidas adotadas para a proteção da fauna e flora na Estrada Parque Morro do Diabo.

PALAVRAS-CHAVE: Acidentes. Estrada Parque. Unidade de Conservação.

\section{ABSTRACT}

The analysis of accidents can provide fundamental information capable of promoting the planning and the construction of plant and equipment, road operations, and actions to improve safety on the roads, especially in stretches located inside of conservation unite. In this work we study if road accidents on State Highway 613 SP, with emphasis in the near and inside the Morro do Diabo State Park (Teodoro Sampaio, SP). The data showed that in the period from 2012 to 2016, 16\% of accidents with animals at 613 SP occurred on the stretch of road Devil's Hill Park. It was observed a reduction of accidents from 2015 which may be related to installation of speed control devices in the stretch of Park Road. The results reinforce the importance of the measures to protect the wildlife on the roads, especially in natural areas rich in biodiversity as conservation units. However, the need that systematic monitoring of the trampling of animals is continuously performed, in order to allow for better evaluating the effectiveness of the measures adopted for the protection of wildlife in the Park Road to the Morro do Diabo.

KEYWORDS: Accidents. Road Park. Conservation Unit.

\section{RESUMEN}

El análisis de los accidentes puede proporcionar informaciones fundamentales capaces de promover la planificación y la construcción de instalaciones y equipos, las operaciones viales, y las acciones para aumentar la seguridad en las carreteras, sobre todo en los tramos ubicados en el interior de unidades de conservación. En este trabajo se estudian accidentes de carretera en la Carretera Estadual SP 613, con énfasis en los tramos cercanos y en el interior del Parque Estadual Morro do Diabo (Teodoro Sampaio, SP). Los datos obtenidos revelan que en el período de 2012 a 2016,16\% de los accidentes con animales en la SP 613 ocurrieron en el tramo de la Estrada Parque Morro do Diabo. Se observó una reducción de los accidentes a partir de 2015 que puede estar relacionada a la instalación de dispositivos de control de velocidad (lomo electrónico) en el tramo de la Estrada Parque. Los resultados refuerzan la importancia de la implantación de medidas para la protección de la fauna silvestre en las carreteras, especialmente en áreas naturales ricas en biodiversidad como las unidades de conservación. Sin embargo, se resalta la necesidad de que el monitoreo sistemático de los accidentes en general sea continuamente efectuado, para permitir mejor evaluar la eficacia de las medidas adoptadas para la protección de la fauna y flora en la Carretera Parque Morro do Diabo.

CONTRASEÑAS: Accidentes. Carreteras parques. Unidades de conservación 


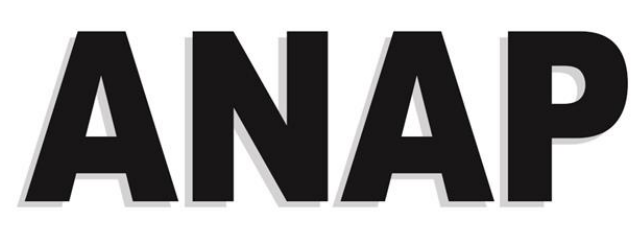

\section{REVISTA CIENTÍFICA}

\section{8}

\section{INTRODUÇão}

As unidades de conservação estão sujeitas a riscos ambientais associados à ocupação humana em seu entorno, que ameaçam a sua integridade ecológica (De Fries et al, 2010) e reduzem a sua biodiversidade (Gaston et al., 2008). Dentre as muitas atividades humanas que ameaçam as unidades de conservação, a implantação de estradas é, sem dúvida, uma das mais preocupantes, porque são fortes "consumidoras" de recursos naturais e geram severos impactos em seu entorno.

A fragmentação de habitats e o atropelamento de animais silvestres representam algumas das mais significativas ameaças à biodiversidade das unidades de conservação impactadas por estradas (Primack e Rodrigues, 2001). Por isso, planejar, projetar, construir, manter e operar sistemas viários são imperativos para minimizar os impactos e, ao mesmo tempo, garantir a função socioeconômica da via.

Os danos ambientais produzidos pelas rodovias são muitas vezes mal dimensionados e, como consequência, as soluções oferecidas não resultam em serviços sustentáveis. $E$ as dificuldades parecem mais severas em ambientes frágeis e ricos em biodiversidade, como é o caso das unidades de conservação, em que os requisitos da estrada carecem maior e melhor adequação às condições do meio.

Dessa forma, entende-se a importância do estudo de dados estatísticos acerca de acidentes de trânsito em rodovias e a importância de mecanismos para a sua prevenção. Por outro lado, as condições operacionais, a geometria, os materiais e os métodos construtivos, e até o interesse dos usuários da via não são o mesmo quando se comparam as estradas tradicionais e as estradas parques.

No Estado de São Paulo, a edição do Decreto № 53146, em 2008, foi importante para a gestão ambiental das estradas em unidades de conservação. $O$ decreto impõe ao órgão responsável pela implantação e operação da estrada pública inserida em unidade de conservação de proteção integral, providenciar um Plano de Implantação e um Plano de Gestão e Operação para cada trecho de estrada (São Paulo, 2008). Para a elaboração desses planos, entretanto, é fundamental conhecer as medidas mais indicadas para minimizar a interferência das estradas nas unidades de conservação, especialmente em relação aos impactos sobre a fauna.

O Decreto № 53146 é conhecido como "decreto estrada parque", apesar de não existir no Estado de São Paulo tal categoria de área protegida. Tampouco existem referências à categoria estrada parque nas classificações adotadas pelos órgãos reguladores da área de transportes no Brasil, como observado em DNIT (2006) e DNIT (2017). Ribeiro e Lima (2017) sugerem que a definição de estradas parque esteja mais associada às qualidades simultâneas de integração ambiental e manutenção das condições de 

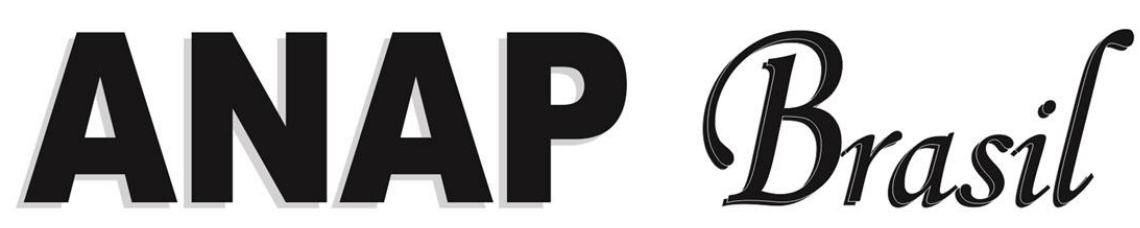

\section{ISSN 1984-3240 V. 11, n. 23}

\section{REVISTA CIENTÍFICA 2018}

tráfego, empregando equipamentos e serviços que incluem, por exemplo: restrições operacionais, projeto e materiais especiais, controle de acessos, instalações para a proteção dos animais e do ambiente, além de estímulo ao turismo e ao lazer.

O registro e a análise dos acidentes podem fomentar procedimentos e indicadores para medir a eficácia dos dispositivos de controle e dos equipamentos de proteção da fauna silvestre. Tal análise pode, ainda, colaborar para melhorar o planejamento e o projeto de estradas, monitorar as operações do tráfego, com reflexos promissores sobre a manutenção da qualidade ambiental em seu entorno.

O número de estudos que avaliam a eficácia de medidas implementadas nas rodovias brasileiras para a proteção da fauna, entretanto, ainda é escasso (Bagatini, 2006). Ao mesmo tempo, há vários estudos que investigam os atropelamentos de animais nas estradas brasileiras, incluindo aquelas que cortam ou margeiam unidades de conservação, como pode ser observado nos trabalhos de Bagatini (2006), Faria e Pires (2012), Oliveira (2013), Martin (2015), Santos (2017).

Estudos que avaliem a eficácia de medidas e serviços em estradas para a proteção da fauna são especialmente relevantes no trajeto em unidades de conservação. É o caso, por exemplo, dos $14 \mathrm{~km}$ da Rodovia Estadual SP 613 no Parque Estadual Morro do Diabo (PEMD). Este trecho da rodovia apresentava elevado índice de atropelamentos de animais silvestres (55 animais atropelados entre 2002 e 2010), de acordo com Faria e Pires (2012). Ainda segundo esses autores, a partir de 2011 a rodovia no PEMD recebeu um conjunto de medidas para a proteção da fauna.

O monitoramento dos atropelamentos de animais em rodovias é uma fonte importante de informações para embasar estudos posteriores relativos à eficácia das medidas ali implantadas. Nesse sentido, o presente trabalho busca contribuir com a avaliação da eficácia das medidas adotadas na Rodovia Estadual SP 613, empregando como referência os acidentes rodoviários envolvendo ou não animais silvestres, e foco especial no trecho em que a estrada atravessa o PEMD.

\section{OBJETIVOS}

Compilar informações e registros de acidentes em rodovias tradicionais e em estradas parques.

Comparar as taxas de acidentes em estradas tradicionais e estradas parques, notadamente na estrada do Morro do Diabo.

\section{METODOLOGIA}

\subsection{O AMBIENTE DE ESTUDOS}



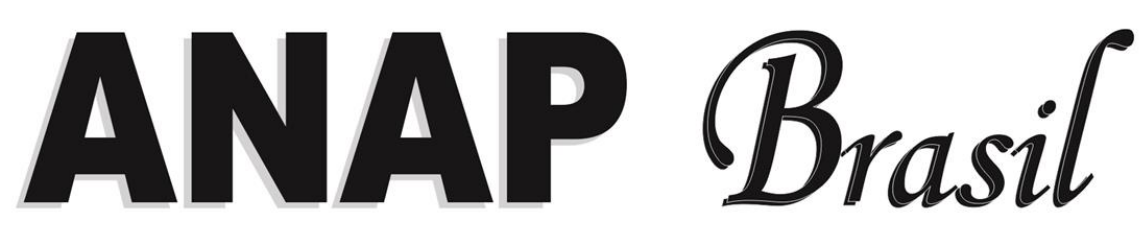

\section{ISSN 1984-3240 V. 11, n. 23}

\section{REVISTA CIENTÍFICA $\quad 2018$}

\section{a) O Parque Estadual Morro do Diabo}

O Parque Estadual Morro do Diabo é uma Unidade de Conservação de proteção integral localizada no Município de Teodoro Sampaio, na região denominada Pontal do Paranapanema, situado no sudoeste do Estado de São Paulo. A região insere-se no bioma Mata Atlântica, e o PEMD representa a maior amostra de Floresta Tropical Estacional Semidecidual do Estado. A Reserva Estadual do Morro do Diabo foi instituída pelo Decreto $\mathrm{N}^{\circ} 12279$, de 29 de outubro de 1941 e, depois, elevada à categoria de Parque Estadual por meio do Decreto $\mathrm{N}^{\circ} 25342$, de 04 de junho de 1886 (Faria e Pires, 2006). Atualmente, o Parque é administrado pela Fundação para Conservação e a Produção Florestal (Fundação Florestal) do Estado de São Paulo e o seu mais recente plano de manejo foi aprovado em 2006 (São Paulo, 2017).

Dentre as espécies vegetais típicas desse ecossistema podem ser citadas o cedro, o ipê, a peroba-rosa, a cabreúva e o pau-marfim. Na fauna do parque se encontram espécies de médio porte e grandes mamíferos quase extintos nessa região do Brasil como a anta, onça-pintada, a onça-parda, o caititu. O mico-leão-preto, é a espécie mais característica do Parque, sendo um dos primatas mais ameaçados do mundo.

O Parque Estadual Morro do Diabo também conta com um grande atrativo turístico: uma trilha que recebe dezenas de visitantes diariamente e, segundo o diretor da unidade, em 2017 foram mais de 20 mil visitantes. Além disso, o local também apresenta trilhas para bicicletas e locais para a pesca ou passeios de barco.

As Figuras 1 e 2 mostram respectivamente o portal de entrada na estrada que corta 0 parque e uma imagem área do parque, em que é possível observar a grandeza da unidade e a estrada que o corta ao meio. 


\section{ANAP

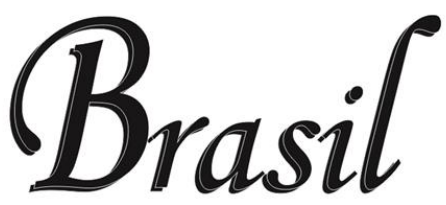 \\ ISSN 1984-3240 \\ v. 11, n. 23}

\section{REVISTA C I ENTÍF I C A $\quad 2018$}

Figura 1: Parque Estadual Morro do Diabo.

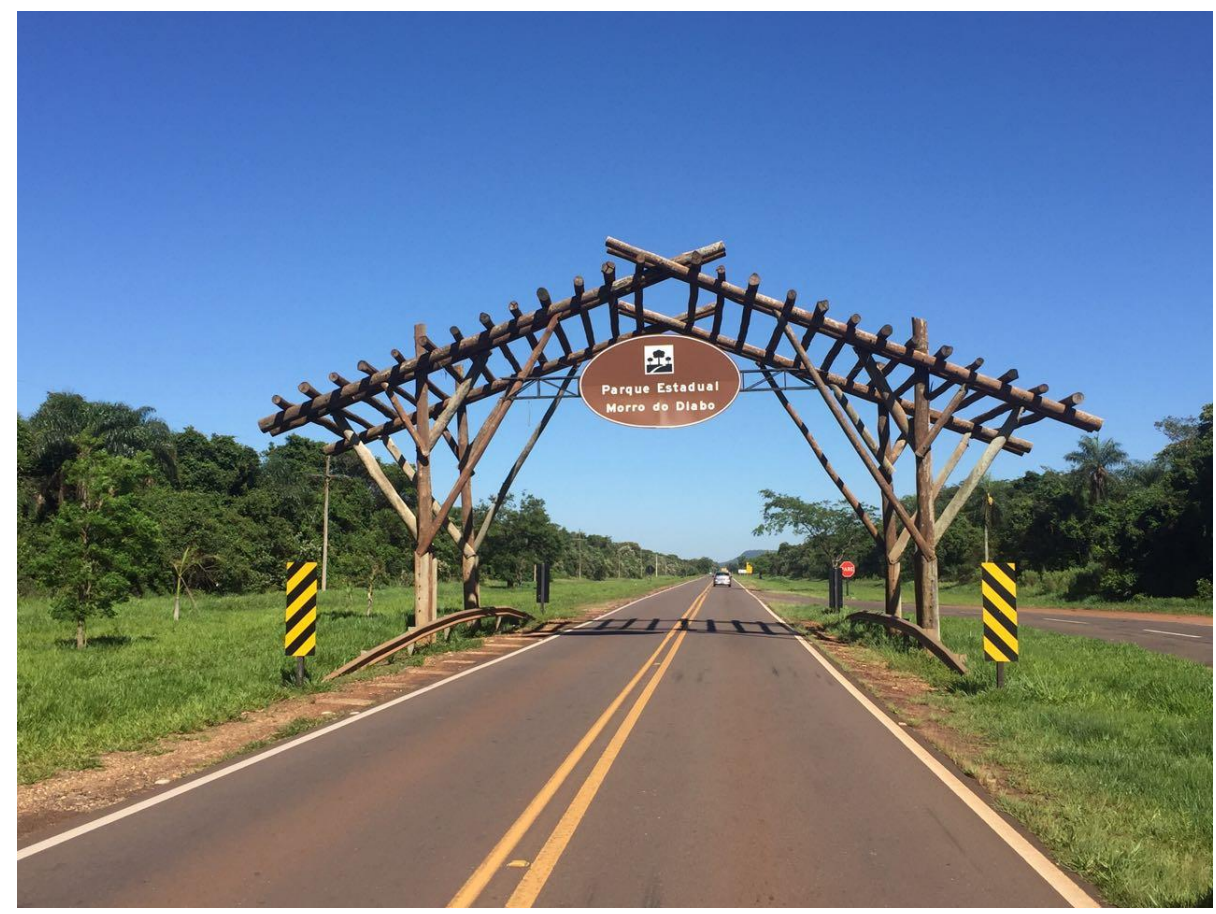

Fonte: elaborado pelo autor, 2018.

Figura 2: Vista do parque e da Rodovia Estadual SP 613.

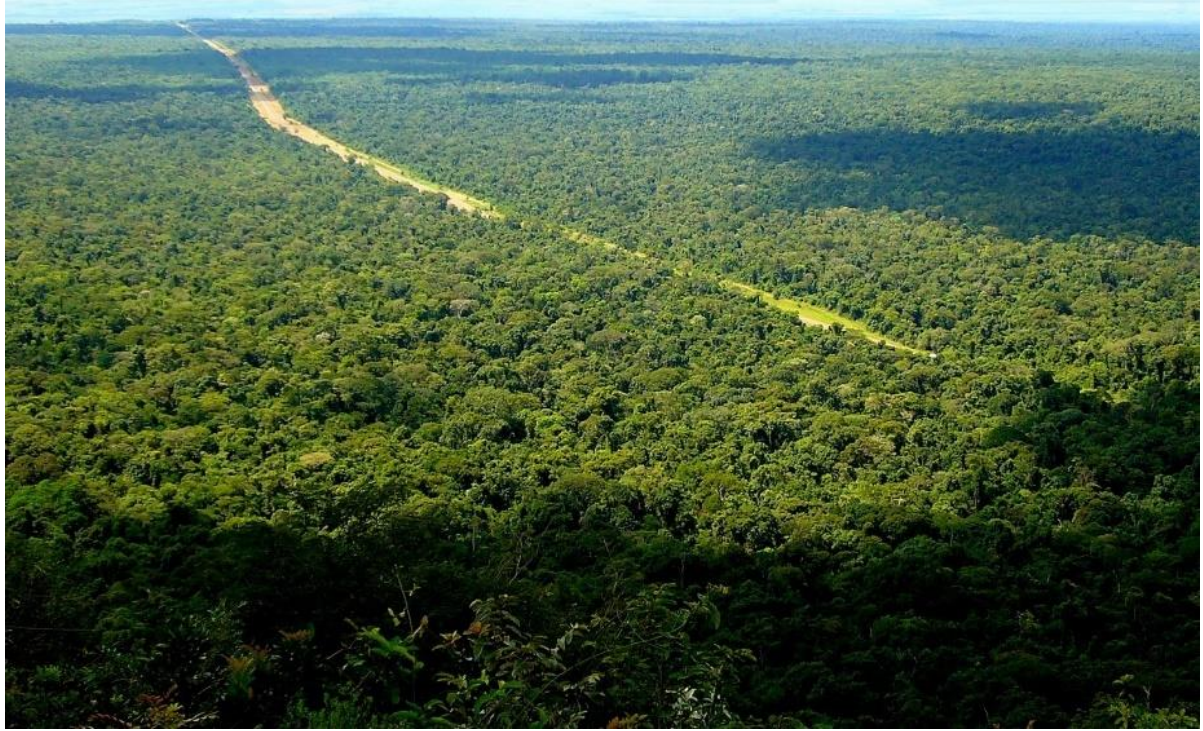

Fonte: http://pemorrododiabo.blogspot.com.br/p/trilha-do-morro-do-diabo.html, 2018. 


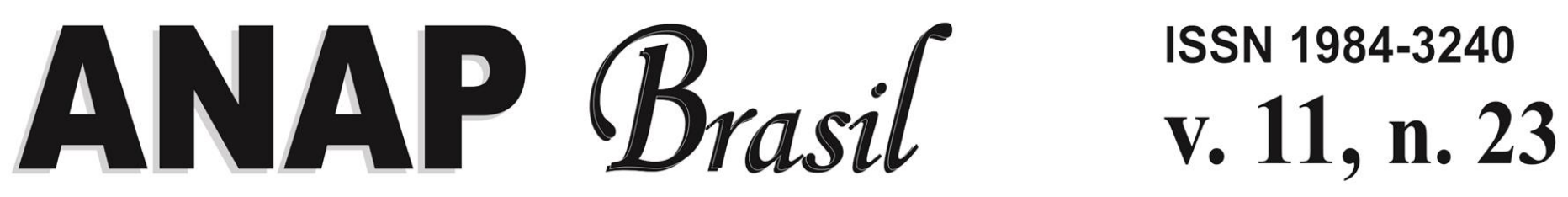

\section{REVISTA C I E N TÍFICA $\quad 2018$}

\section{b) A Rodovia Estadual SP 613 (Arlindo Bettio)}

A Rodovia Estadual SP 613 (chamada Rodovia Arlindo Bettio), foi construída nos anos 1970 como estrada de terra carroçável e secundária (classificação DNIT, 2017). Depois, o seu traçado e geometria foram alterados e ela, então, foi pavimentada mantendo as características atuais. A via é uma pista simples com duas faixas e duplo sentido de tráfego. A largura total da plataforma de rolamento é de aproximados 7,0m com revestimento asfáltico. O acostamento é irregular, com cascalho e pavimento remanescente com largura variável de 1,5 até 2,0m. O trecho da Rodovia Estadual SP 613 em análise tem 93,6 km de extensão e liga os municípios de Rosana, Euclides da Cunha e Teodoro Sampaio. A Figura 3 destaca o trecho da SP 613 em questão.

Figura 3: Imagem da Rodovia SP-613 em estudo.

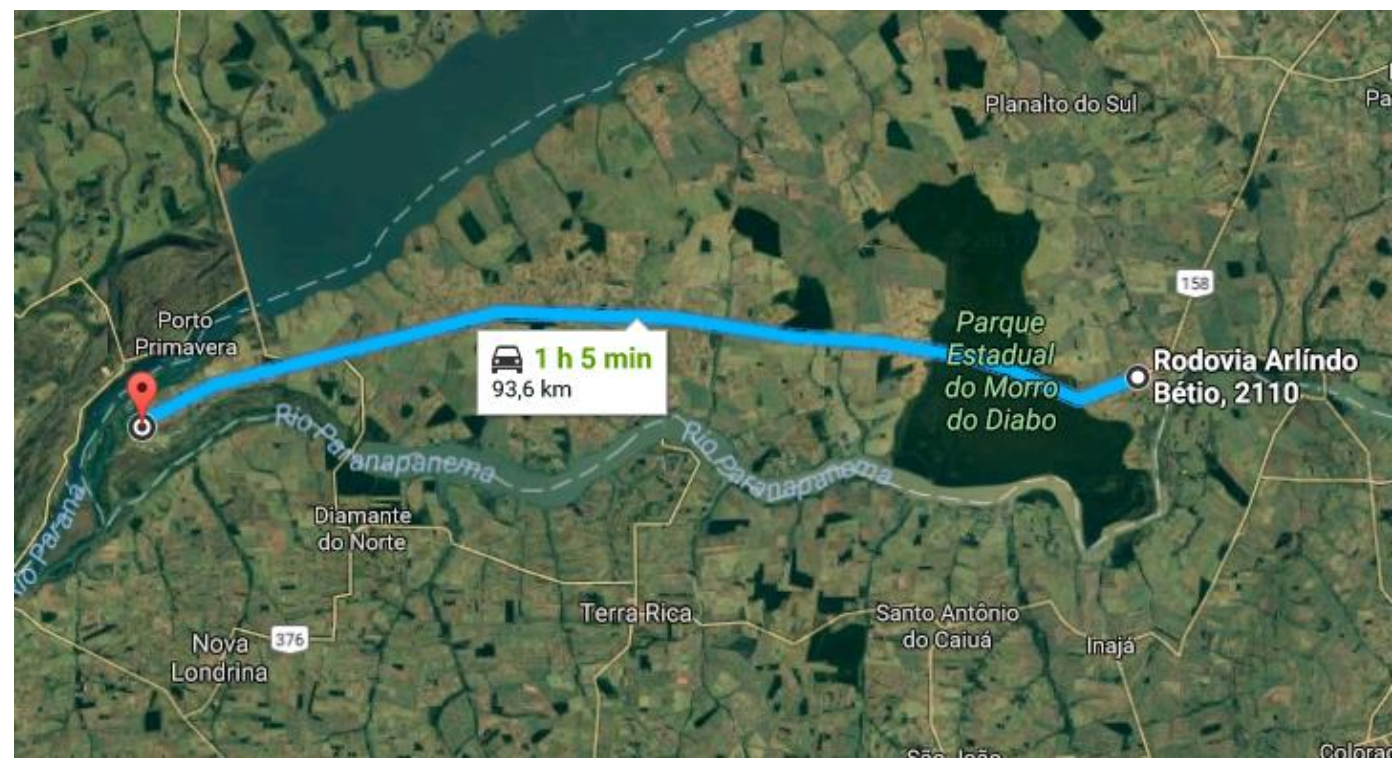

Fonte: google mapas, 2018.

\section{c) A Estrada Parque Morro do Diabo}

A Portaria SUP/DER-025-10/06/2015 que disciplina o código para as rodovias estaduais paulistas e seus principais pontos de passagem identifica a SP 613 na categoria de rodovias. As características de projeto (geometria, construção, materiais e controle de serviços) são semelhantes nos trechos dentro e fora do parque. O volume diário médio de tráfego (VDM) também é o mesmo nos dois casos: 2.500 (2012); 2.587 (2013); 2.687 (2014); 2.770 (2015); e 2.745 (2016) (DER SP, 2017a).

Todavia, existem algumas diferenças operacionais nos 14 quilômetros da estrada parque, como a velocidade máxima que é de $70 \mathrm{~km} / \mathrm{h}$ no parque e $100 \mathrm{~km} / \mathrm{h}$ no 


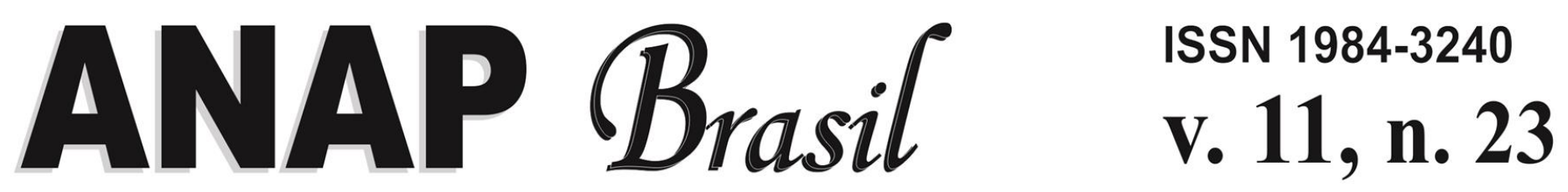

\section{REVISTA CIENTÍFICA $\quad 2018$}

restante da via. Também dentro do parque existem 4 radares (medidores de velocidades), diversas placas informativas, 8 túneis de passagem de animais (zoopassagens), portal de entrada e saída da estrada. E a administração deste trecho é realizada pelo Parque Estadual Morro do Diabo em parceria com a Polícia Rodoviária.

A Relação Descritiva das Rodovias Estaduais Paulistas (DRE SP, 2017) classifica a SP 613 apenas como rodovia, sem distinção ao trecho no PMED. Entretanto, o segmento de $14 \mathrm{~km}$ da SP 613 que atravessa o Parque Estadual Morro do Diabo é considerado como Estrada Parque (Eriqui Marqueti Inazaki - gestor do parque, comunicação pessoal, 2017). A Figura 4 destaca o trecho da estrada parque que atravessa e unidade de conservação.

Figura 4: Imagem da Rodovia Arlindo Béttio, com destaque para o trecho da estrada parque.

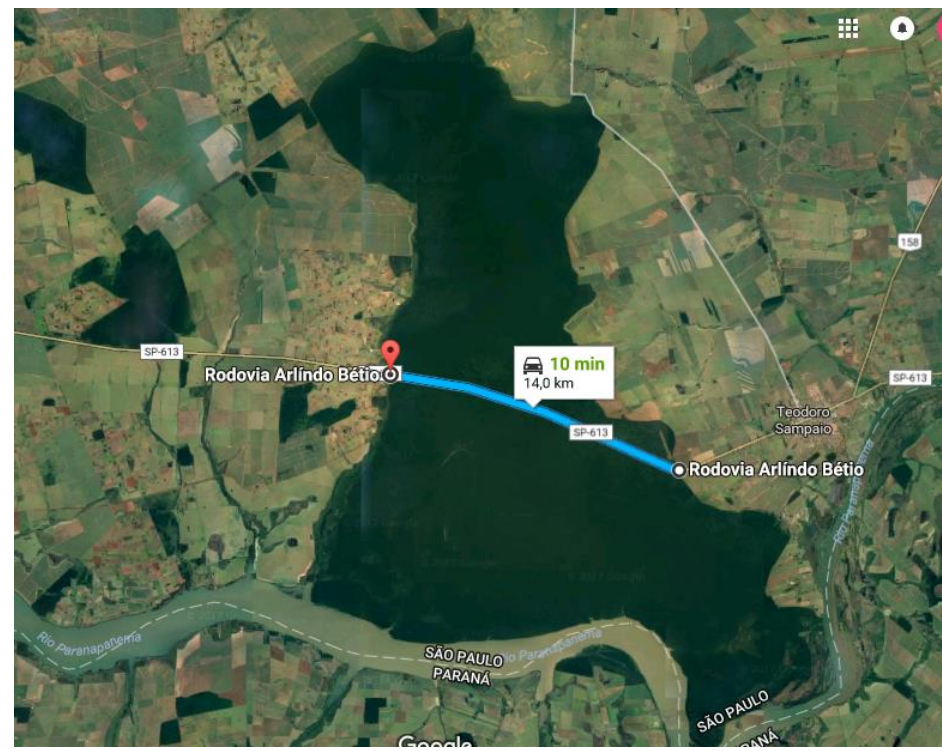

Fonte: google mapas, 2018.

Na estrada parque Morro do Diabo a distância do acostamento até a mata alcança menos de 3 metros, em alguns trechos. Tais condições facilitam a circulação de animais próximos à estrada e reforçam a necessidade dos acessórios de proteção e das restrições operacionais na via.

A Figura 5 identifica um dos radares para o controle de velocidade. Ressalta-se que a velocidade máxima neste trecho é de $70 \mathrm{~km} / \mathrm{h}$. 


\section{ANAP

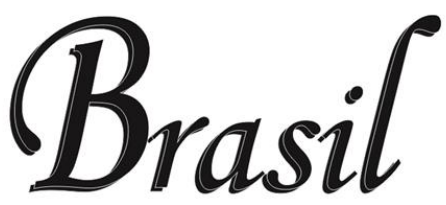 \\ ISSN 1984-3240 \\ v. 11, n. 23}

\section{REVISTA C IENTÍFICA $\quad 2018$}

Figura 5: Radar dentro da estrada parque.

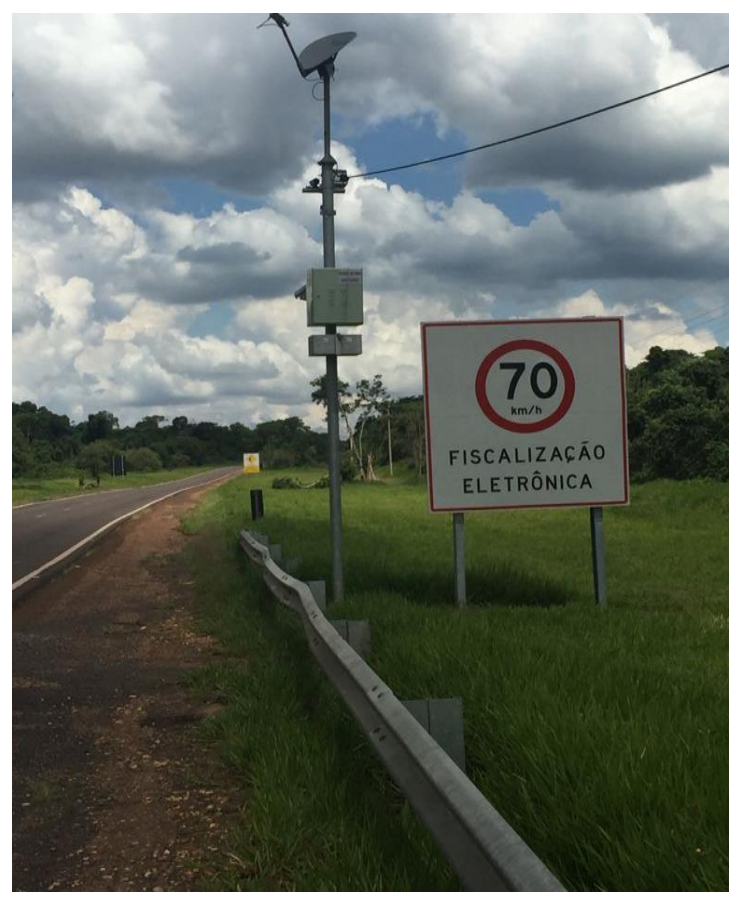

Fonte: elaborado pelo autor., 2018.

A Figura 6 mostra um dos túneis de passagem da fauna silvestre.

Figura 6: Túnel de passagem da fauna silvestre.

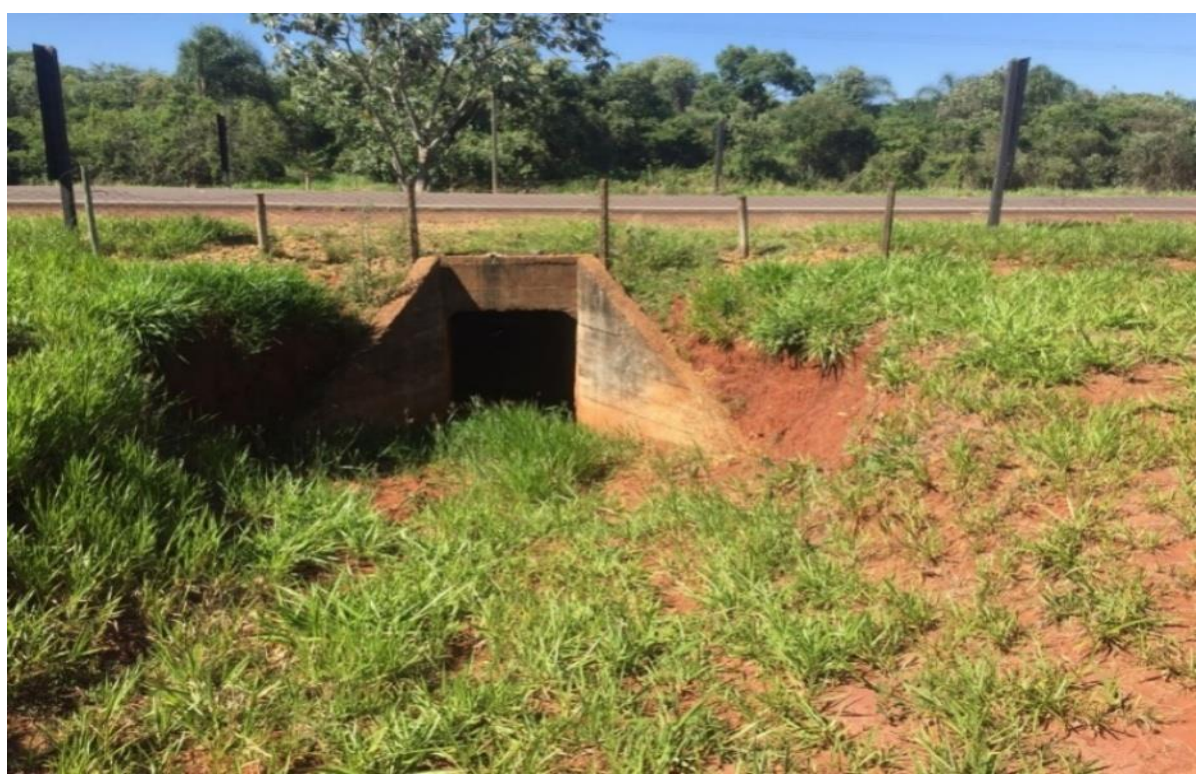

Fonte: elaborado pelo autor, 2018. 


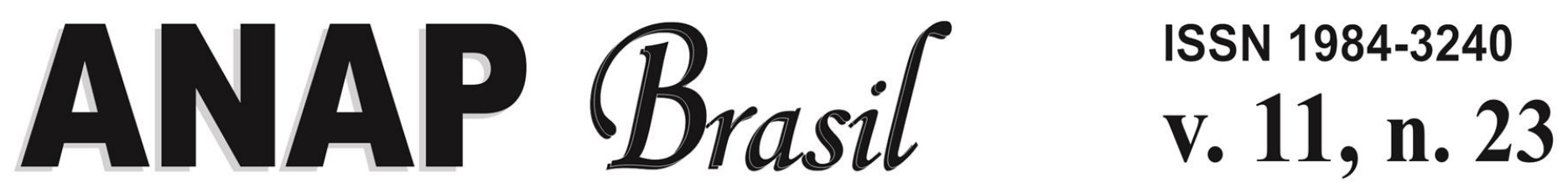

\section{REVISTA C I ENTÍF I C A $\quad 2018$}

A Figura 7 detalha pegadas de animais que passaram pelo túnel, sugerindo que 0 dispositivo apresenta eficácia.

Figura 7: Pegadas de animais próximas ao túnel de passagem de fauna.

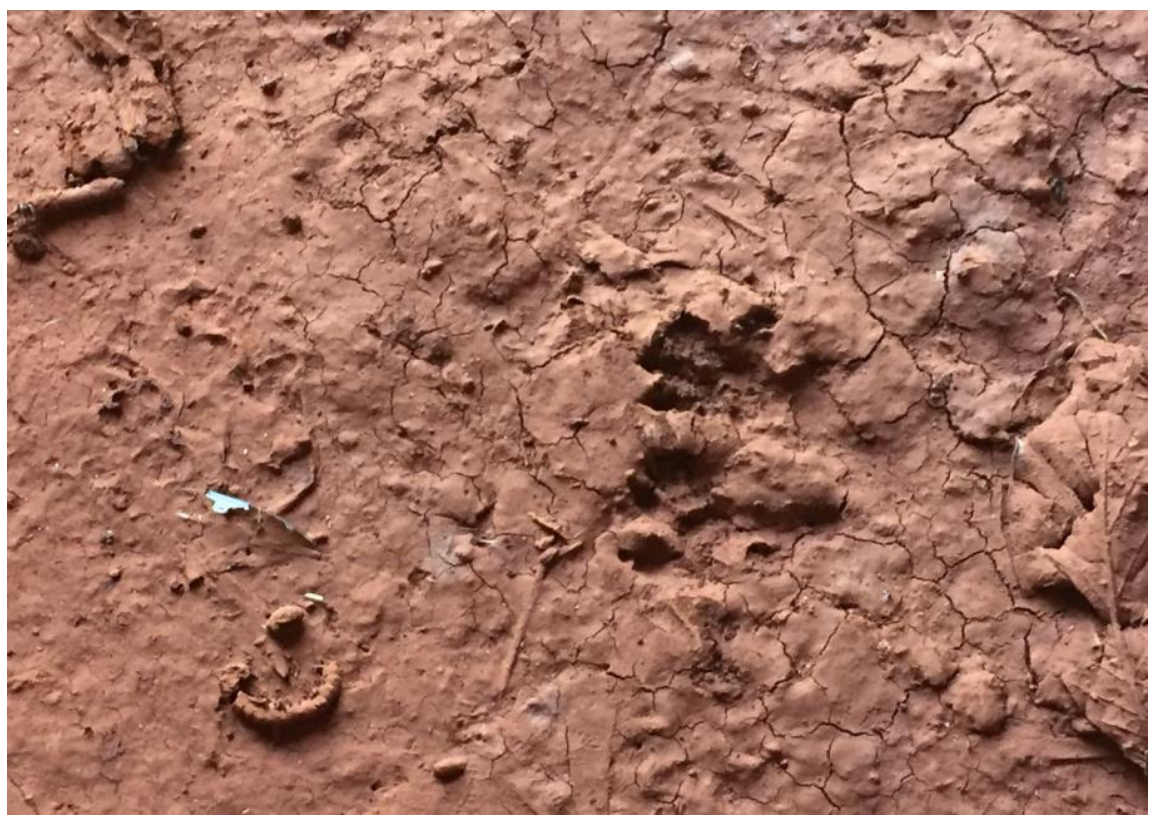

Fonte: elaborado pelo autor, 2018.

\subsection{A COLETA DE DADOS}

Os dados de acidentes em geral e atropelamentos de animais silvestres foram compilados para o período de 2012 até 2016, com base em cadastros da Polícia Rodoviária Estadual (SP). Também há registros do DER-SP, complementados com informações obtidas in loco.

\subsection{METODO DE ANÁLISE}

Para análise dos dados, estudou-se dois tipos de acidentes, os acidentes em geral, os quais são as incidências de todos os tipos de acidentes, e os atropelamentos de animais, que são apenas ocorrências as quais animais foram atropelados.

Para estudo dos acidentes na estrada parque e nos trechos próximos ao parque, dividiu-se a estrada em 4 sub trechos. Os quais podem serem observados na figura 8. 


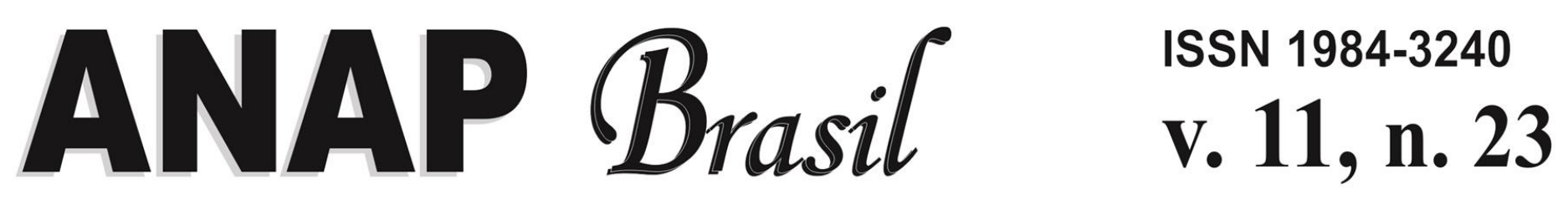

\section{REVISTA C I EN TÍF I C A $\quad 2018$}

Figura 8: Sub trechos para estudo.

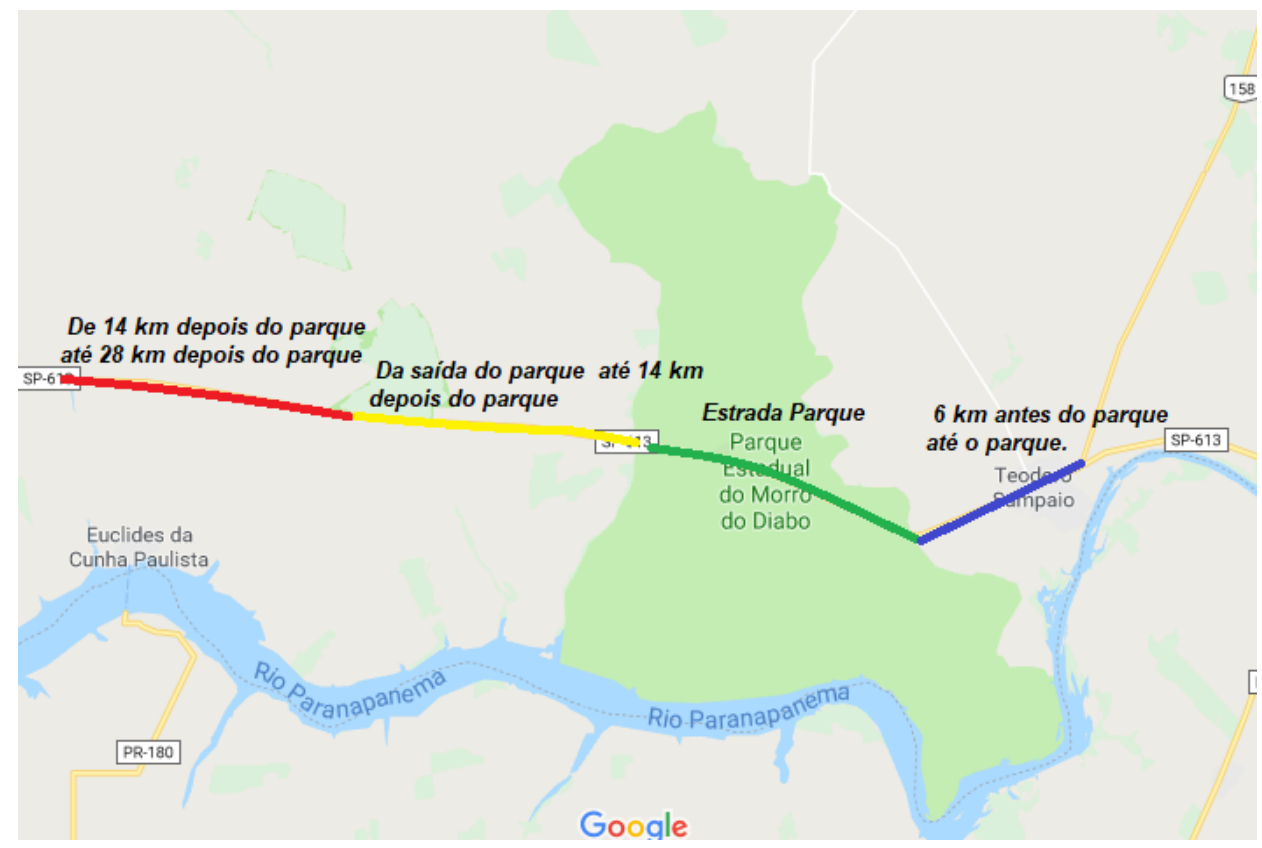

Fonte: google mapas, 2018-modificado.

Para a análise também foram utilizados os trechos nomeados como "Na estrada parque" (dentro da estrada parque) e "Fora da estrada parque" (que considera toda rodovia SP-613).

\section{DADOS E ANALISES}

\subsection{PROBLEMÁTICAS DA ESTRADA PARQUE E DA UNIDADE DE CONSERVAÇÃO}

Os maiores problemas na SP-613 são as constantes mortes de animais silvestres e os incêndios florestais. Em relação aos animais, um monitoramento levado a cabo entre 1989 e 1999 apontou que 25 espécies da fauna sofreram redução de suas populações em função dos atropelamentos (FARIA; MORENI, 2000).

Por outro lado, o número de animais mortos encontrados não representa de fato o número real. Em alguns casos os animais atropelados não morrem no momento da colisão e se refugiam na mata ou podem ser arrastados para fora das margens de pista por outro animal e muitos dos atropelamentos não são contabilizados pela polícia, devido ao pequeno porte dos animais. Estas mortes não são contabilizadas. Tomando por base tais premissas, aliadas aos 182 animais encontrados no período considerado, pesquisadores realizaram uma extrapolação estatística e concluíram que o número estimado de animais mortos poderia a até 1.200 em 10 anos (Plano de Manejo PEMD2006). 


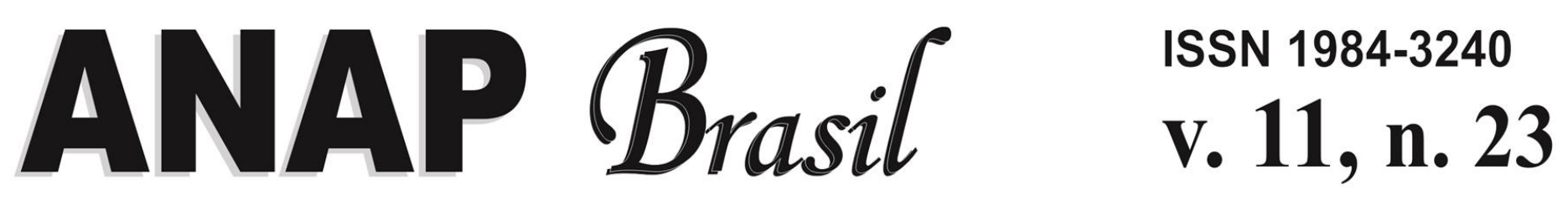

\section{REVISTA C I ENTÍFICA $\quad 2018$}

Devido a este cenário, o Ministério Público moveu uma ação contra o Departamento de Estradas de Rodagem - DER (Inquérito Civil 002/1991) para que o órgão tomasse as medidas com vistas a cessar ou diminuir os impactos negativos da estrada sobre a biota do parque. Como consequência, um conjunto de medidas foi adotado para a proteção ambiental. Dentre elas, destacam-se: portais nos acessos; sinalização especial; gestão e fiscalização compartilhadas; aceiro nas laterais da pista; túneis para a passagem de fauna (08 dispositivos); lombadas eletrônicas (radares, 04 dispositivos); campanhas de educação aos usuários; mata nativa nos limites da faixa de domínio da estrada.

\subsection{ACIDENTES NA ESTRADA PARQUE MORRO DO DIABO}

\subsubsection{Acidentes Dentro e Fora da Estrada Parque}

Para o presente estudo a SP-613 foi classificada em 4 sub trechos, com segmentos fora e dentro da estrada parque. Os gráficos das Figuras 9 e 10 indicam o número acumulados de acidentes em geral e atropelamentos de animais dentro e fora da estrada parque para os anos 2012, 2013, 2014, 2015 e 2016, conforme os dados da Policia Rodoviária.

Figura 9: Acidentes em geral, por quilômetro, dentro e fora da estrada parque.

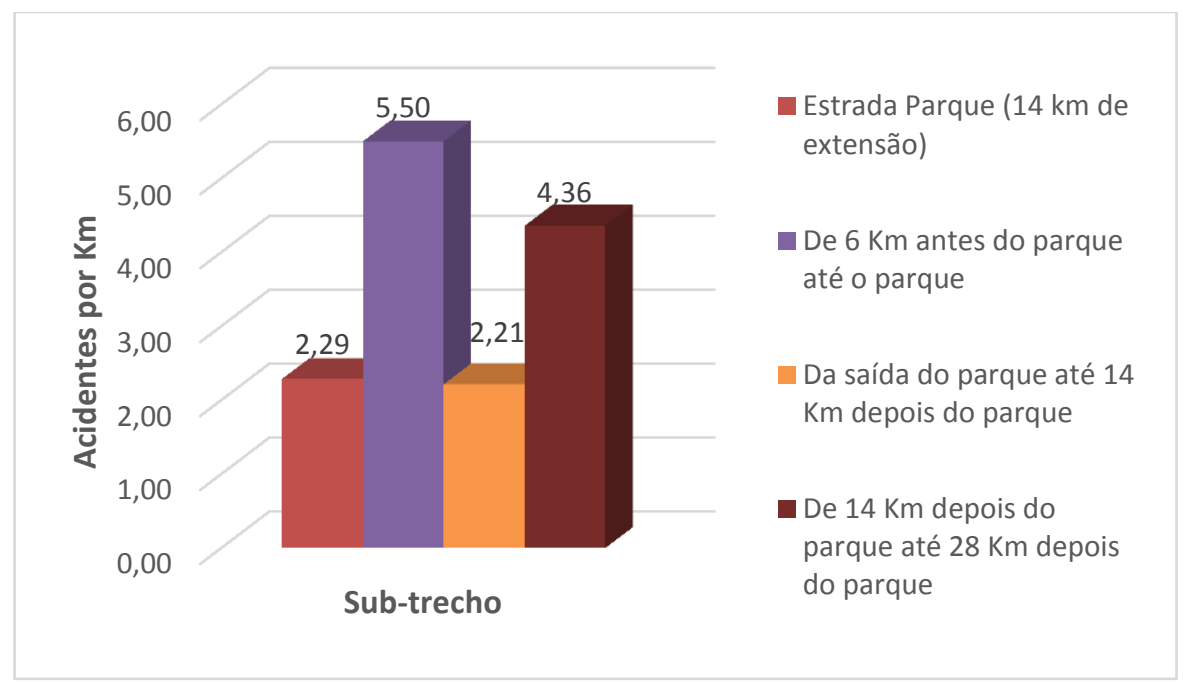

Fonte: elaborado pelo autor, 2018.

Com esses dados, afirma-se que em torno do Parque Estadual Morro do Diabo o maior índice de acidentes por $\mathrm{km}$ ocorre no trecho de $6 \mathrm{~km}$ antes do parque até o parque com 5,5 acidentes por $\mathrm{Km}$. Trecho o qual passa por um trecho urbano da cidade de Teodoro Sampaio-SP e termina no portal da estrada parque.

O menor número de acidentes dentro do parque pode ser justificado pela fiscalização ostensiva na Estrada Parque, dado a presença de radares e placas de advertência, as 

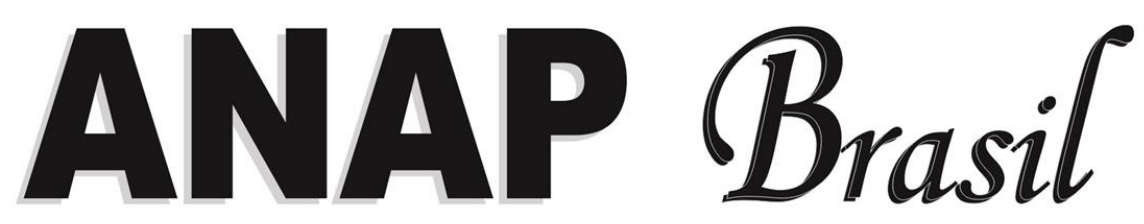

\section{ISSN 1984-3240 V. 11, n. 23}

\section{REVISTA CIENTÍFICA 2018}

campanhas de educação, portais de sinalização e menor velocidade $(70 \mathrm{~km} / \mathrm{h})$. Este conjunto de equipamentos e acessórios implica maior atenção dos usuários e controle das operações.

Mesmo assim, o número absoluto de acidentes ainda é mais elevado em outro sub trecho do que na Estrada Parque. As marcas de pneus próximas aos dispositivos de controle de velocidade denotam uma característica típica dos condutores brasileiros: a insistente inobservância às regras de trânsito. Vale ressaltar que em 2015 (sem os radares) houveram sete acidentes e em 2016 (após a instalação dos equipamentos) foram nove acidentes.

Uma alternativa para o problema seria a instalação de radares que fiscalizam a velocidade média no trecho da estrada parque, de modo que force aos motoristas respeitarem as velocidades permitidas, assim dando maior segurança vida das pessoas e dos animais que lá habitam.

Figura 10: Atropelamentos por quilômetro dentro e fora da estrada parque.

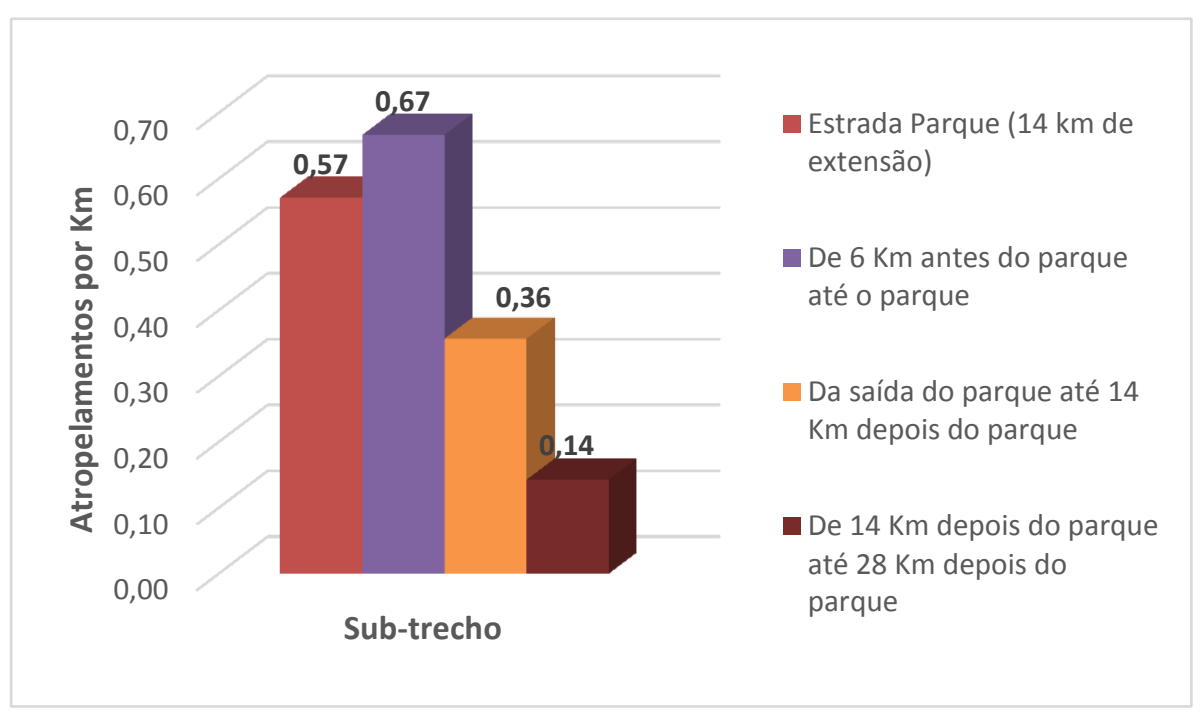

Fonte: elaborado pelo autor, 2018.

A figura do gráfico 10 demonstra a quantidade de atropelamentos de animais, dentro do parque e em sub trechos próximos ao parque. De modo que o maior índice de atropelamentos ocorridos foi no trecho de $6 \mathrm{~km}$ de extensão, antes do parque (o qual vai do $\mathrm{Km} 0$ da rodovia Arlindo Bettio até o $\mathrm{Km} \mathrm{6}$, onde se inicia a estrada parque).

Isso indica a existência de animais em trechos próximos a unidade de conservação, mostrando que eles não atravessam a rodovia somente em trechos da estrada parque. E que medidas de prevenção ao atropelamento de animais também deveriam serem tomadas nesses locais. 


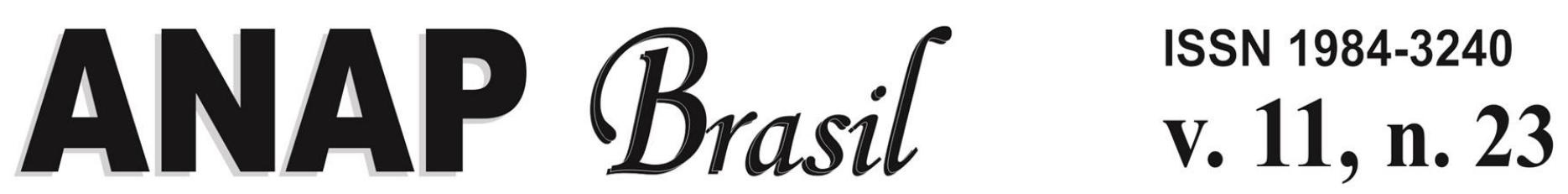

\section{REVISTA C I ENTÍFICA $\quad 2018$}

Esses dados também comprovam a parte da eficácia dos mecanismos operacionais, para a prevenção de atropelamentos de animais, na estrada parque. Já que se sugere que dentro da estrada parque o número de animais é muito maior do que nos outros trechos.

\subsubsection{Análise dos Acidentes por Quilometro}

O número de acidentes em geral ou atropelamentos ambos por quilômetro é um fator que agrega informações importantes sobre a segurança da via, para veículos e animais. Neste caso, a análise considera trechos dentro e fora da estrada parque. $O$ gráfico da Figura 11 ilustra o número de acidentes em geral por quilometro, dentro e fora da estrada parque, nos anos de 2012 até 2016.

Figura 11: Relação de acidentes em geral por quilômetro SP-613.

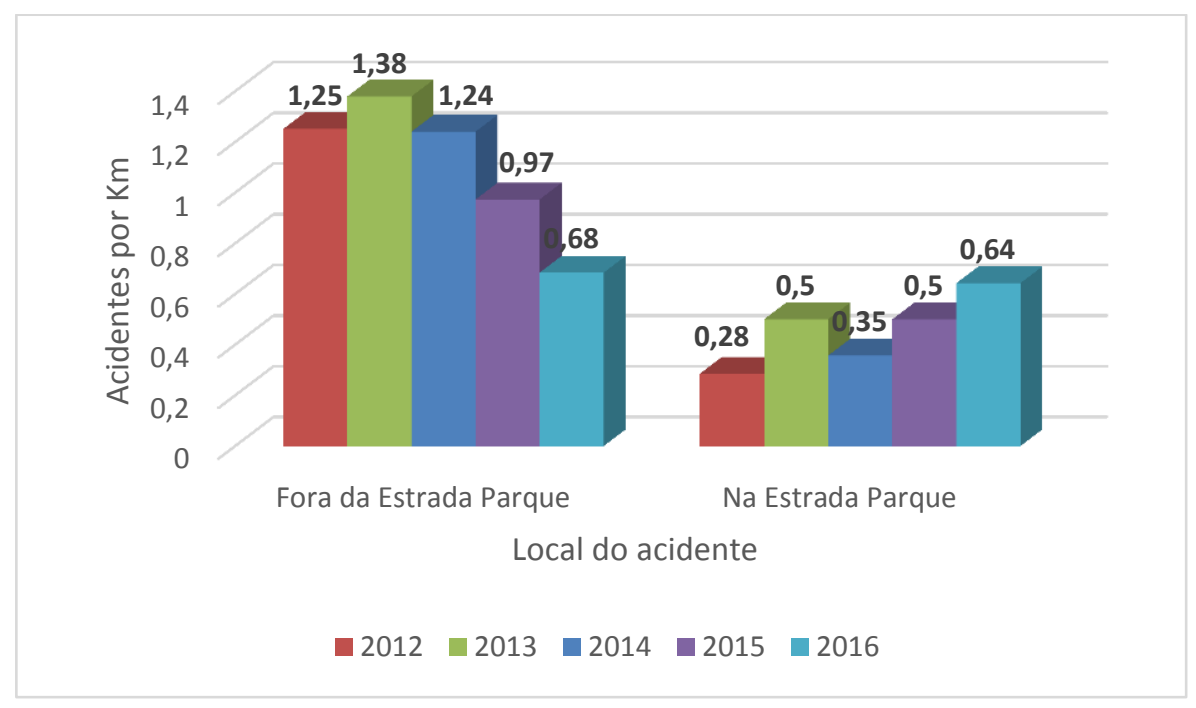

Fonte: elaborado pelo autor, 2018.

Em todos os anos analisados o número de acidentes por quilômetro fora da estrada parque é maior que o número dentro da estrada parque. E em alguns anos esse valor chegou a ser mais de 4 vezes maior. Isso demonstra que a Estrada Parque é mais segura que o restante da rodovia, ao considerar todos os tipos de acidentes.

Todavia, percebe-se um aumento do índice de acidentes dentro da estrada parque no ano de 2015 e 2016, sendo que os radares foram instalados em 2015. Isso indica o não respeito a velocidade média da via, dentro do parque. Ao contrário disso, fora da estrada parque o número de acidentes tem se reduzido, o que demonstra maior segurança da rodovia por inteira.

A maior segurança da via pode ser justificada pela combinação de fatores que inclui maior fiscalização e respeito à sinalização e legislação de trânsito, eficácia dos 


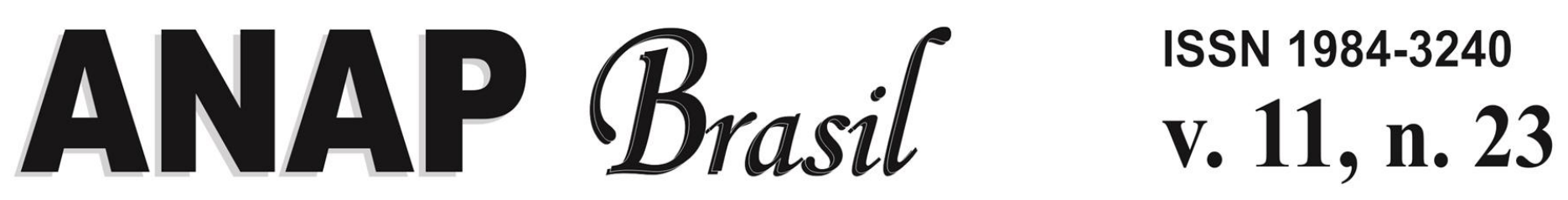

\section{REVISTA C I ENTÍFICA $\quad 2018$}

dispositivos de segurança instalados, utilização de veículos mais modernos. Por outro lado, a qualidade da via oferece segurança aos usuários em suas viagens.

Outro dado que pode estar relacionado à segurança das operações na via é o número anual de atropelamentos de animais por quilômetro. Esta relação está descrita no gráfico da Figura 12, para valores dentro e fora da estrada parque nos anos de 2012 a 2016.

Figura 12: Atropelamentos por quilômetro na estrada parque Morro do Diabo e na SP-613.

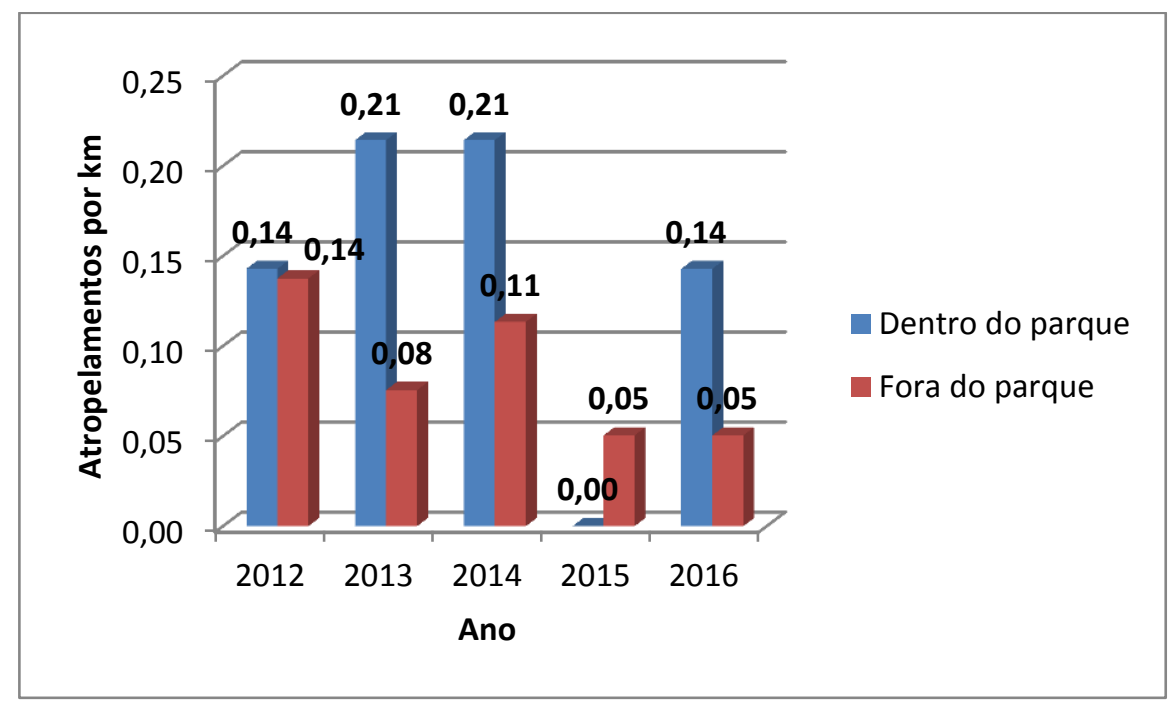

Fonte: elaborado pelo autor, 2018.

O gráfico da Figura 12 indica que o número de atropelamentos por $\mathrm{km}$, dentro do parque foi maior em 2013, 2014 e 2016, com grande diferença entre eles. Apenas em 2015 o número de atropelamentos por quilômetro foi menor na estrada parque. Em 2012 os números foram praticamente iguais. Esses índices reforçam a importância das campanhas para a conscientização dos usuários e da instalação de medidas de preservação ambiental e de acidentes dentro do PEMD.

Nesse contexto, percebe-se que o número de atropelamento por $\mathrm{km}$ se reduziu nos anos 2015 e 2016 dentro da estrada parque, mesmo com um aumento no número de acidentes em geral. Com isso, observa-se a eficácia dos radares, dentro do parque, devido a diminuição dos números de atropelamento de animais, visto que esses foram instalados em pontos onde os atropelamentos aconteciam com maiores frequências.

Também é importante citar que de acordo com registros da Polícia Rodoviária Estadual, 88,1\% dos acidentes notificados com animais (acumulados entre $2012 \mathrm{e}$ 2016) acontecem no período noturno, já que os animais da unidade são em sua maioria de hábitos noturnos. 


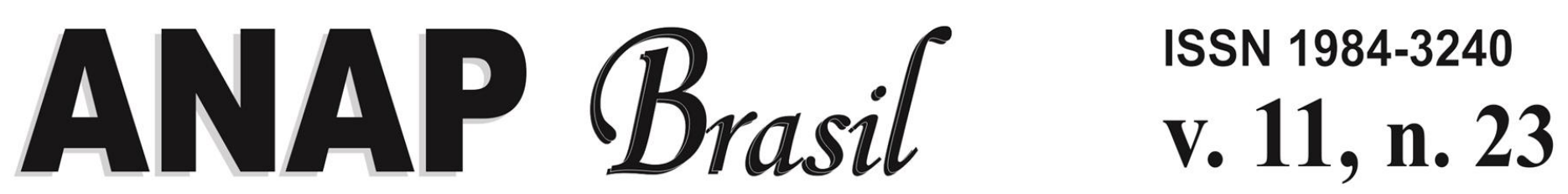

\section{REVISTA C I ENTÍFICA $\quad 2018$}

Tais informações são importantes para o planejamento das estradas, das instalações e serviços, e dos dispositivos de controle operacional, de preservação ambiental e prevenção de acidentes.

\subsection{ANÁLISES DOS ACIDENTES DA SP-613 EM COMPARAÇÃO COM O NÚMERO DE ACIDENTES EM RODOVIAS DA REGIÃO}

O gráfico da Figura 13 detalha a distribuição dos acidentes por quilometro nas rodovias SP-501, SP-613, SP-272 e na estrada parque, considerando os nos anos de 2015 e 2016. Esta relação pode ser útil para comparar estradas localizadas na macrorregião dos estudos e que apresentam características geométricas e de tráfego similares.

Figura 13: Atropelamentos por quilômetro em estradas da região.

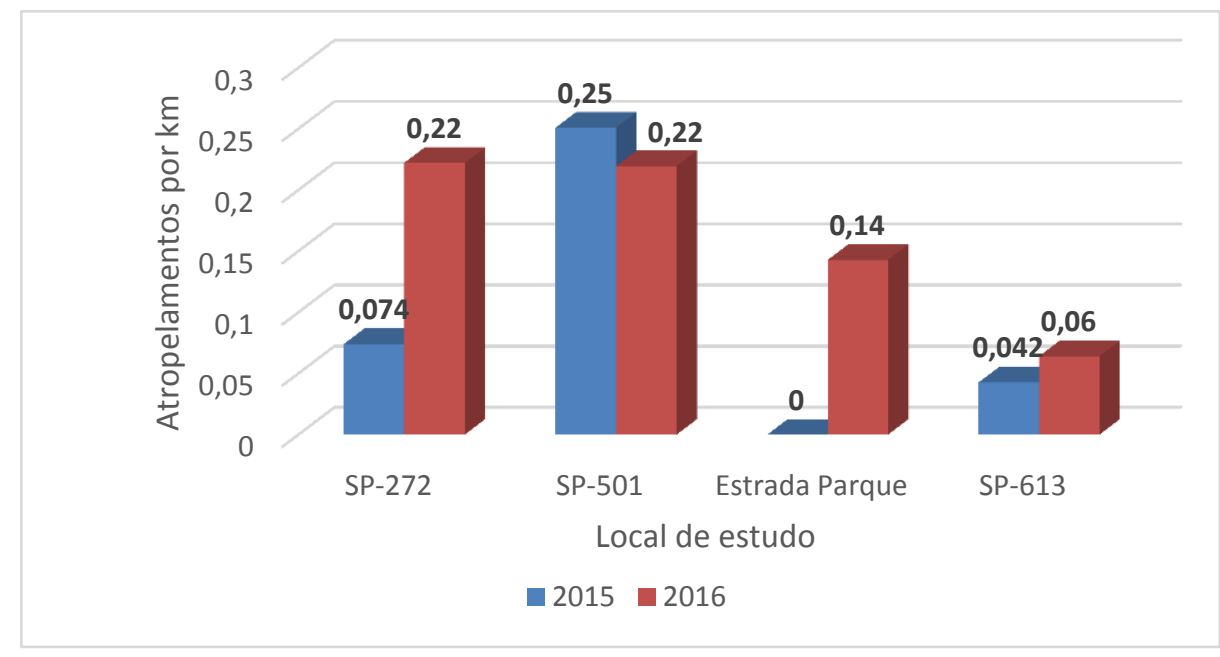

Fonte: elaborado pelo autor, 2018.

De acordo com os dados apresentados, a SP-613 parece mais segura que Rodovias SP501 e 272 quanto ao item atropelamento de animais. Estes dados "positivos" podem ser resultantes dos mecanismos de prevenção de acidentes com animais ao longo da estrada parque. Ressalte-se que a localização da estrada parque em uma unidade de conservação ambiental agrega potencial para promover maior interação entre os usuários e os animais. E que, mesmo assim, o número de acidentes ali é menor do que os registrados em outras rodovias da região.

\section{CONCLUSÕES}

De acordo com os dados cadastrados, a estrada parque é o trecho mais seguro da Rodovia SP-613, quanto aos acidentes em geral. Da mesma forma, é também mais segura que as outras rodovias da região (SP-501 e SP-563) quanto ao volume de acidentes por quilômetro. 


\section{REVISTA CIENTÍFICA 2018}

Com relação ao número de atropelamentos de animais por $\mathrm{km}$, a estrada parque ainda apresenta elevados índices, todavia esses se apresentam reduzidos ao se entender que a estrada passa dentro de uma unidade de conservação e tem grande quantidade de animais.

A maior segurança na estrada parque está relacionada às diferenças operacionais decorrentes de programas de educação, sinalização especial, da fiscalização, e dos equipamentos e acessórios de controle das operações e de proteção da fauna e da flora silvestres.

A maior segurança da estrada parque é benéfica também para a unidade de conservação, uma vez que os acidentes (e não apenas o atropelamento de animais) podem produzir grandes impactos ambientais. Dentre os riscos destacam-se: incêndios, contaminação do solo e da água, perda de vegetação lindeira, morte ou migração de animais, maior vulnerabilidade aos agentes tóxicos e produtos e animais exóticos, mudanças de hábito e de habitat dos animais.

Nesse contexto, estimam-se ganhos significativos no cenário de integração estrada versus ambiente, se o planejamento da estrada acontecer na fase que antecede 0 projeto. Entretanto, como foi possível perceber nesse trabalho, mesmo intervenções posteriores para agregar à rodovia acabada equipamentos, instalações e serviços típicos da estrada parque, podem resultar em benefícios ambientais consideráveis.

Os mecanismos de prevenção de acidentes dentro do parque são eficazes e de grande importância para a preservação da unidade de conservação. Mesmo assim, propostas que se traduzam em benefícios sociais e ambientais no contexto das estradas e rodovias carecem de afinidades com o meio onde está a obra. De maneira geral, estudos prévios para definir os tipos, os procedimentos e os materiais adequados se revelam imperativo para o sucesso das intervenções, sobretudo em ambientes frágeis.

\section{REFERÊNCIAS BIBLIOGRÁFICAS}

BAGATINI, T. 2006. Evolução dos índices de atropelamento de vertebrados silvestres nas rodovias do entorno da estação ecológica Águas Emendadas. UNB, Brasília. Dissertação (Mestrado em Ecologia).

DE FRIES, R.; KARANTH, K. K.; PAREETH, S. Interactions between protected areas and their surroundings in human-dominated tropical landscapes. Biological Conservation, v.143, p.2870-2880, 2010.

DER SP. Departamento de Estradas de Rodagem. Secretaria de Logística e Transportes. Relação descritiva das rodovias estaduais. São Paulo, SP. 2017. Disponível em: 


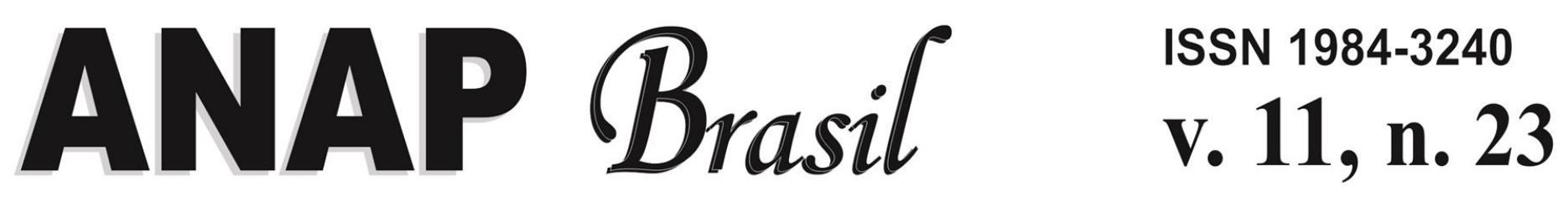

\section{REVISTA C I E N TÍ F I C A $\quad 2018$}

http://www.der.sp.gov.br/Website/Acessos/Institucional/Denominacoes.aspx. Acesso em 18/11/2017.

DER SP. Departamento de Estradas de Rodagem. Secretaria de Logística e Transportes. Estatística de tráfego. São Paulo, SP. 2017. Disponível em: http://www.der.sp.gov.br/WebSite/Acessos/MalhaRodoviaria/VolumeDiario.aspx. Acesso em 18/11/2017.

DNIT. Departamento Nacional de Infra-Estrutura de Transportes. Diretoria de Planejamento e Pesquisa. Coordenação Geral de Estudos e Pesquisa. Instituto de Pesquisas Rodoviárias. Glossário de termos técnicos ambientais rodoviários. Rio de Janeiro, 2006. 116p. (IPR. Publ., 721).

DNIT. Departamento Nacional de Infraestrutura de Transportes. Diretoria Geral. Diretoria de Planejamento e Pesquisa. Coordenação do Instituto de Pesquisas Rodoviárias. Glossário de termos técnicos rodoviários. 2. ed. Rio de Janeiro, 2017. 324p. (IPR Publ. 700).

DNIT. Departamento Nacional de Infraestrutura de Transportes. Anuário Estatístico das Rodovias Federais -Acidentes de trânsito e ações de enfrentamento ao crime. Rio de Janeiro, RJ. 2010.

DNIT. Rio de Janeiro, RJ: CUSTOS DE ACIDENTES DE TRÂNSITO NAS RODOVIAS FEDERAIS, 2004.

DNIT. Rio de Janeiro, RJ: Terminologias rodoviárias usualmente utilizadas, 2007.

DNIT. Rio Janeiro, RJ: Glossário de termos técnicos ambientais rodoviários, 2006.

FARIA, H. H.; PIRES, A. S. (Coord.). Plano de manejo do Parque Estadual Morro do Diabo. Santa Cruz do Rio Pardo: Viena, p. 311. 2006.

FARIA, Helder Henrique; PIRES, Andréa Soares Pires. Rodovia em unidade de conservação: o caso do Parque Estadual do Morro do Diabo, São Paulo, Brasil. VIII Fórum Ambiental da Alta Paulista, v. 8, n. 3, 2012, p. 01-22.

GASTON, K. J.; Jackson, S. F.; Cantú-Salazar, L.; Cruz-Pinõn, G. The ecological performance of protected areas. Ann. Rev. Ecol. Evol. Syst., 39, 93-103, 2008.

MARTIN, C. F. 2015. Monitoramento de fauna silvestre atropelada no entorno da Estação Ecológica de Carijós. UFSC. Florianópolis. 


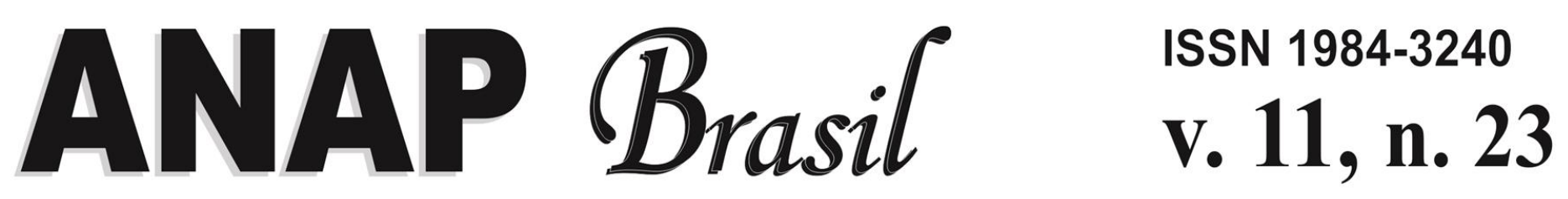

REVISTA C I E N TÍF I C A $\quad 2018$

PRIMACK, Richard B.; RODRIGUES, Efraim. Biologia da Conservação. Londrina, Gráfica Editora Midiograf, 2001.

RIBEIRO, D. R.; LIMA, J. S. P. Estradas parque do ponto de vista da infraestrutura de transportes. XIII Fórum Ambiental da Alta Paulista. Unesp. Tupã, SP. 2017.

RODRIGUES, V. A. Levantamento de animais silvestres atropelados na Rodovia SP 613 que corta o Parque Estadual Morro do Diabo - SP. Trabalho de Conclusão, apresentado a Faculdade de Ciências, Letras e Educação, Curso de Ciências Biológicas Bacharelado, Universidade do Oeste Paulista. Presidente Prudente, SP. 2013. 37p.

SANTOS, R. A. L. 2017. Dinâmica de atropelamento de fauna silvestre no entorno de unidades de conservação do Distrito Federal. UNB. Brasília.

SÃO PAULO (estado). Fundação Florestal. Parque Estadual do Morro do Diabo: plano de manejo, 2006.

SÃO PAULO (estado). Fundação Florestal. Planos de manejo. Disponível em: http://fflorestal.sp.gov.br/pagina-inicial/planos-de-manejo/planos-de-manejo-planosconcluidos/. Acesso em novembro de 2017. 